\title{
Morphological evaluation of the mandibular lingula using cone-beam computed tomography
}

\author{
B. Senel ${ }^{1}$, A. Ozkann ${ }^{2}$, H.A. Altug ${ }^{3}$ \\ ${ }^{1}$ Gulhane Military Medical Academy, Department of Oral and Maxillofacial Radiology, Ankara, Turkey \\ ${ }^{2}$ Gulhane Military Medical Academy and Turkish Land Forces, Oral and Maxillofacial Surgery, Ankara, Turkey \\ ${ }^{3}$ Gulhane Military Medical Academy, Department of Oral and Maxillofacial Surgery, Ankara, Turkey
}

[Received 19 January 2015; Accepted 2 February 2015]

\begin{abstract}
Background: Lingula is a tongue-like flap of bone that overlaps the mandibular foramen antero-medially and location is clinically significant in oral and maxillofacial surgeries. The aim of this study was to assess the shape and precise location of lingula using cone-beam computed tomography (CBCT).

Materials and methods: In this study, 3-dimensional images provided by CBCT of 63 patients (28 females, 35 males, age range 25-70 years) were retrospectively evaluated. All CBCT images were performed due to implant planning. From both sides of 63 mandibles were classified in the following shapes: triangular, truncated, nodular and assimilated. The location was determined by 5 distances from the lingula: the anterior and the posterior borders of the mandibular ramus, mandibular notch and lover border of mandible. Height of the lingula was measured from the lingular tip to the mandibular foramen.

Results: Nodular shape of lingula was the most commonly found (32.5\%). The mean distance of lingula from anterior and posterior borders of mandibular ramus was $18.5 \pm 2.3$ and $16.9 \pm 3.5 \mathrm{~mm}$, respectively. The lingula was located at $18.1 \pm 3.6 \mathrm{~mm}$ from the mandibular notch and $38.3 \mathrm{~mm}$ from the lover border of mandible. The mean height of lingula was $7.8 \pm 2.4 \mathrm{~mm}$.

Conclusions: The present study provides the morphological variation and localization of the lingula. The lingula is an important clinical landmark for mandibular osteotomy, and for determining the distance to mandibular foramen entrance. (Folia Morphol 2015; 74, 4: 497-502)
\end{abstract}

Key words: cone-beam computed tomography, intraoperative complications, mandible, morphology, mandibular osteotomy

\section{INTRODUCTION}

The lingula of the mandible is a tongue-shaped bony prominence which overlaps the mandibular foramen. It provides attachment for sphenomandibular ligament. Because of the close proximity of lingula to the mandibular foramen and neurovascular bundles [5], it is used as an important clinical landmark for oral and maxillofacial surgical procedures such as sagittal split ramus osteotomy (SSRO) [6], mandibular trauma management, eradication of benign and malignant lesions, pre-prosthetic surgery, and avoiding nerve injury during inferior mandibular nerve block [15, 24].

Accurate estimation for position of the lingula is essential during the administration of local anaesthe- 
tic because the anaesthetic solution being deposited in the region of the lingula of the mandible. Inadequate knowledge of the anatomy of the medial aspect of the ramus may result in failure of the mandibular block, or more importantly, damage to the inferior alveolar or lingual nerves. In addition, morphological characteristics of the mandibular foramen and lingula may account for failure to inferior mandibular nerve block $[9,11,18]$.

The increased use of diagnostic imaging acquired by means of cone-beam computed tomography (CBCT) has led to various studies of anatomical structures and possible anatomical differences [7]. Three-dimensional (3D) reconstructed images from CBCT are more reliable and accurate than $2 \mathrm{D}$ radiography of craniofacial structures for diagnosis, and allow multiple imaging post-processing protocols for better and more effective treatment planning and evaluation $[3,10]$. Thus, many investigators chose $3 \mathrm{D}$ analysis to evaluate mandibular morphology, especially the latest development of CBCT which could help to provide better image resolution, shorten acquisition time, reduce the radiation dose, and lower costs [14].

Lingula is a reliable anatomic landmark to determine the position of the mandibular foramen. This study aims to identify the shape and localisation of the lingula of mandibles in Southeast Region of Turkey using $\mathrm{CBCT}$, proposing to guide oral and maxillofacial surgeons to perform safer a surgical procedure.

\section{MATERIALS AND METHODS}

Sixty three subjects underwent $\mathrm{CBCT}$ examination of the mandible for implant therapy. There were 35 males and 28 females, with an average age of 46 years, ranging from 25 to 70 years. CBCT images were acquired using an i-CAT CBCT unit (Imaging Sciences International, Inc., Hatfield, PA, USA) operating at $120 \mathrm{kVp}, 8 \mathrm{~mA}$, with $0.25 \mathrm{~mm}$ voxel size and field of view of $13 \mathrm{~cm}$. Once the $3 \mathrm{D}$ images of every sample had been processed, the data was analysed with i-CAT Vision software (Imaging Sciences International), which offers various views of the data.

The shape of the lingula was studied and classified into 4 types: triangular, truncated, nodular, and assimilated type as previously reported by Tuli et al. [25]. The triangular lingula had a wide base and a narrow rounded or pointed apex, whereas a truncated lingula had a quadrangular top. The nodular lingula was nodular and of variable sizes, almost the entire lingula of this type, except for its apex, merged into the ramus. The assimilated lingula was completely incorporated into the ramus (Fig. 1).

The position of the lingula was identified by measuring the distance from the lingula to anterior border of the ramus (a), the posterior border of the ramus (b), the coronoid notch (c), the lover border (d) of mandible. In addition, vertical distance of the lingula to the lower border of the mandibular foramen was measure as height of the lingula (H) (Fig. 2).

A descriptive statistical analysis was performed. For the comparison of each measure $(a, b, c, d, H)$ according to hemi-arch (R: right; L: left), the Student's t-test was used. The $\chi^{2}$ test was used to compare the distribution of lingular types according to gender. For all comparisons, differences were considered with a minimum of $5 \%$ significance level. All statistical analysis was performed using SPSS 14.01 for Windows.

\section{RESULTS}

The types and distribution of the lingula are presented in Table 1. The most frequently encountered shape was the nodular type $(32.5 \%)$. The respective occurrence of the assimilated $(26.2 \%)$, triangular $(22.2 \%)$ and truncated (19\%) types were found. Bilateral shape $(76 \%)$ was found more often than the unilateral shape $(24 \%)$.

The distribution of the lingular shapes was also compared between females and males mandibles. There was no statistically significant difference according to gender. Over all assimilated type is more prevalent in males, whereas nodular shape is seen more often in females (Table 2).

In Table 3, it can be observed that the comparison of each mandibular measure according to hemi-arch. The mean height of the lingula was $7.8 \pm 2.4 \mathrm{~mm}$ and it was $7.4 \pm 2.7 \mathrm{~mm}$ on the left side and $8.3 \pm 2.2 \mathrm{~mm}$ on the right side. The lingula was located at $18.5 \pm 2.3 \mathrm{~mm}$ from anterior border of mandibular ramus, $16.9 \pm 3.5 \mathrm{~mm}$ from the posterior border of the ramus and $18.1 \pm 3.6 \mathrm{~mm}$ from the mandibular notch. The mean distance of lingula from the lower border of mandible was $38.3 \pm 5.3 \mathrm{~mm}$. It was observed no statistically significant difference between the locations of the mandibular foramen according to hemi-arch.

\section{DISCUSSION}

The size and morphology of the anatomical structure can be easily assessed by 3D views with $C B C T$. 

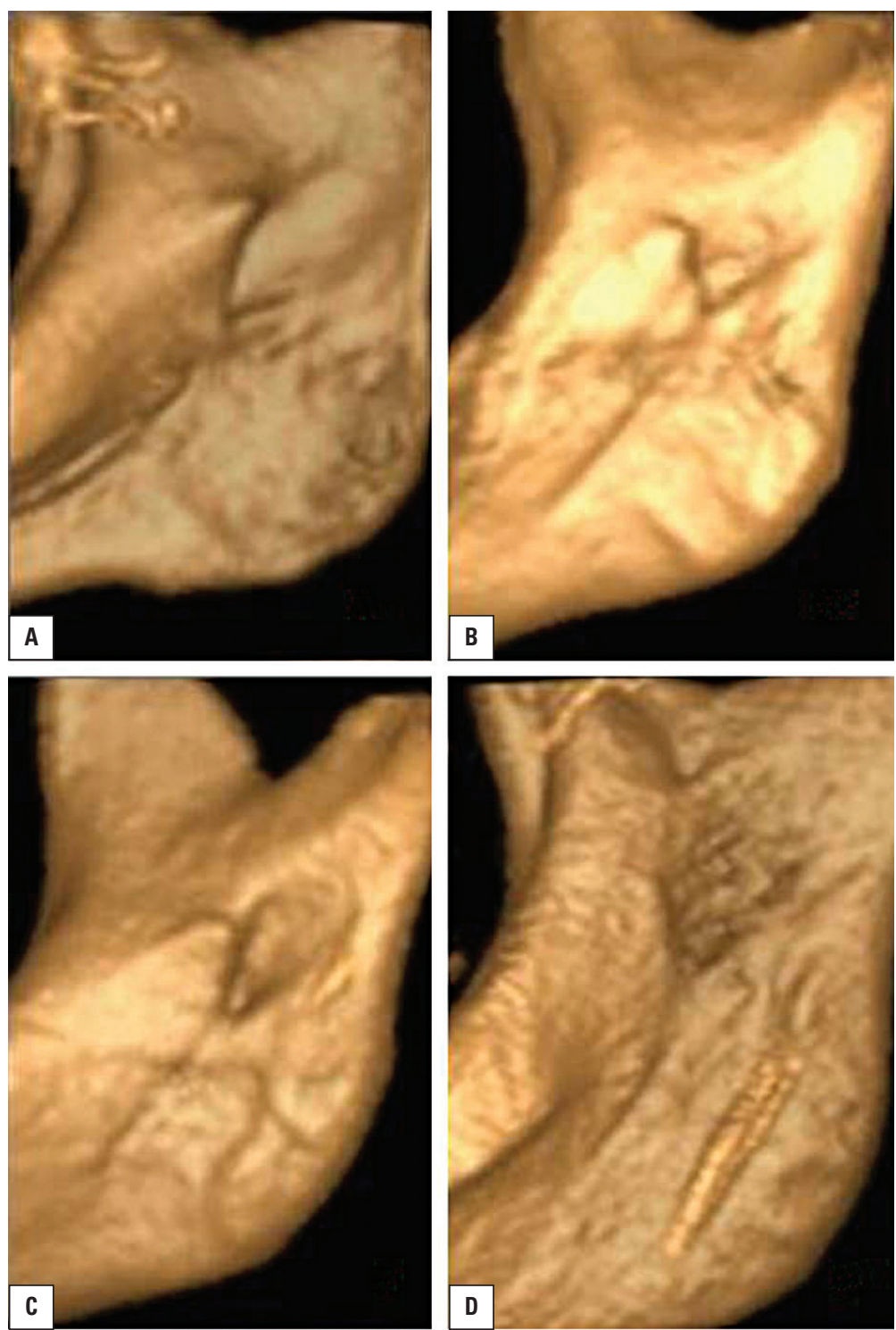

Figure 1. Different shapes of lingula; A. Triangular; B. Truncated; C. Nodular; D. Assimilated.
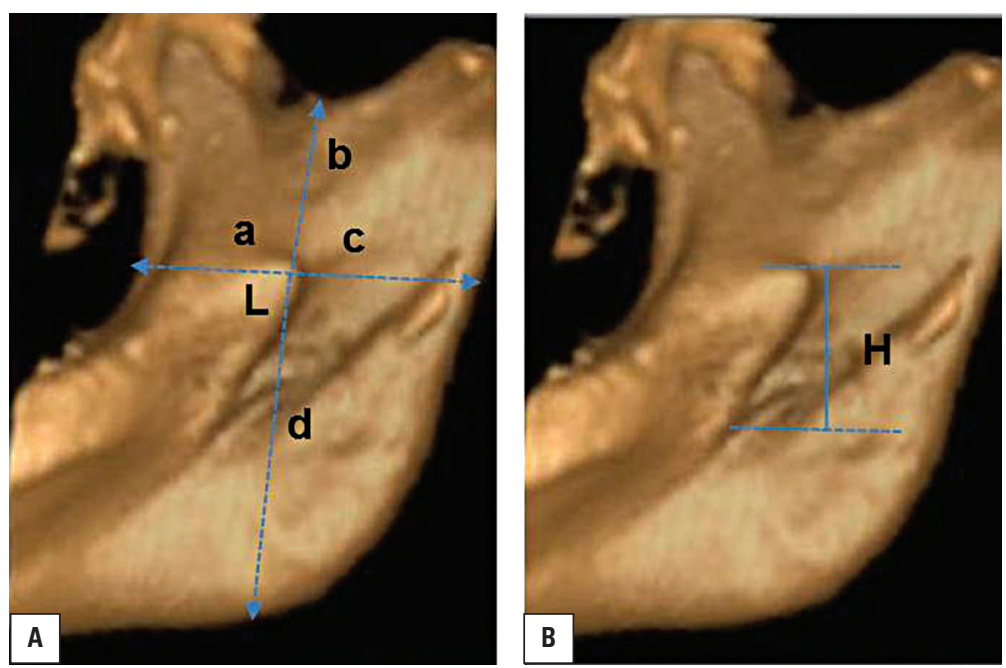

Figure 2. A, B. Measurements of lingula (L) from the various landmarks: $a$ — anterior border; $b$ - posterior border; $c$ - mandibular notch; $d-$ lover border; $\mathrm{H}$ - height of the lingual. 
Table 1. Analysis of the shape of the lingula according to the triangular, truncated, nodular and assimilated classification ( $\mathrm{n}=126$ sides)

\begin{tabular}{lccc}
\hline Shape & Bilateral & \multicolumn{2}{c}{ Unilateral } \\
\cline { 3 - 4 } & & Right & Left \\
\hline Truncated $(n=24,19 \%)$ & 18 & 5 & 1 \\
Triangular $(n=28,22.2 \%)$ & 20 & 2 & 6 \\
Nodular $(n=41,32.5 \%)$ & 32 & 5 & 4 \\
Assimilated $(n=33,26.2 \%)$ & 26 & 3 & 4 \\
Total $(n=126,100 \%)$ & $96(76 \%)$ & $15(12 \%)$ & $15(12 \%)$ \\
\hline
\end{tabular}

Table 2. Variations in shapes of lingula in male and female mandibles ( $\mathrm{n}=126$ sides)

\begin{tabular}{lccc}
\hline Shape & Male & Female & P \\
\hline Truncated & $14(20 \%)$ & $10(17.9 \%)$ & \\
Triangular & $17(24.3 \%)$ & $11(19.6 \%)$ & \\
Nodular & $18(25.7 \%)$ & $23(41.1 \%)$ & 0.320 \\
Assimilated & $21(30 \%)$ & $12(21.4 \%)$ & \\
Total & $70(100 \%)$ & $56(100 \%)$ & \\
\hline
\end{tabular}

3D CBCT craniofacial imaging techniques are becoming increasingly popular and have brought new aspects to morphological assessment [2].

The lingula is defined as a tongue-shaped bony projection on the medial surface of the ramus close to posterior margin of the mandibular foramen. Due to its relationship to the alveolar nerve, the lingula has been a main anatomic landmark to guide surgeons [4]. If oral and maxillofacial surgeons are unable to identify the lingula correctly, intraoperative complications such as haemorrhage, unfavourable fracture and nerve injury may occur [1].

Different morphological shapes of lingula were first described using dry mandibles by Tuli et al. [25] into triangular, truncated, nodular and assimilated types. Other studies were performed using this classification.
Tuli et al. [25] studied 165 dry adult mandibles of Indian origin and found 4 lingual shapes, triangular (68.5\%), truncated $(15.8 \%)$, nodular (10.9\%) and assimilated (4.8\%). Varma and Sameer [26] studied 193 dry adult mandibles and found 5 major shapes by adding $M$ shaped to Tuli's classification and reported nodular type of lingual to be more frequently observed in South Indian population whereas Murlimanju et al. [16] reported both nodular and triangular shapes (29.9\%) occurred most commonly. In Samanta and Kharb [21] study the most prevalent shape of lingula was triangular and the least prevalent shape was assimilated type, agreeing with Tuli et al. [25]. Shenoy et al. [23] found nodular variety of lingual was the most common type which was followed by the truncated, the triangular and the assimilated type on 50 dry mandibles, respectively. In another study on Indian population reported by Nirmale et al. [19] $47.67 \%$ of lingual had triangular shape, $27.97 \%$ were found nodular, $13.69 \%$ were assimilated and $10.71 \%$ were truncated. In the study of Lopes et al. [13] the triangular shape was the most common and assimilated type the least common variety of shape of lingula in the Southern Brazil population. The study on Thai population reported by Kositbowornchai et al. [12] the truncated shape occurred most commonly $(47.2 \%)$ followed by the nodular $(22.9 \%)$, triangular $(16.7 \%)$ and assimilated shapes (13.2\%), which are in accordance with the results of Jansisyanot et al. [8] who studied 92 dry mandibles and the respective occurrence of the truncated, triangular, nodular, and assimilated shapes was 46.2, 29.9, 19.6 and $4.3 \%$. Their results also showed that truncated lingula were most appeared to be bilateral, just as the study of Kositbowornchai et al. [12].

In a retrospective study performed by Sekerci and Sisman [22], in Turkish population using cone beam computed tomographic images, nodular type (51.2\%) of the lingula was most commonly found and the least common was the assimilated type $(2.7 \%)$, truncated and triangular varieties were present in $32 \%$ and $14.1 \%$ of the mandibles, respectively. Also in this study

Table 3. Comparison of each mandibular measure according to hemi-arch ( $\mathrm{n}=126$ sides)

\begin{tabular}{lcccc}
\hline Parameters & Right side [mm] & Left side [mm] & Average [mm] & P \\
\hline Distance from anterior border of ramus & $18.4 \pm 2.2$ & $18.7 \pm 2.5$ & $18.5 \pm 2.3$ & 0.550 \\
Distance from posterior border of ramus & $16.7 \pm 3.3$ & $17.1 \pm 3.8$ & $16.9 \pm 3.5$ & 0.529 \\
Distance from mandibular notch & $18.1 \pm 3.6$ & $18.1 \pm 3.7$ & $18.1 \pm 3.6$ & 0.976 \\
Distance from lover border of mandible & $37.6 \pm 5.5$ & $39.1 \pm 5.1$ & $38.3 \pm 5.3$ & 0.122 \\
Height of the lingula & $8.3 \pm 2.2$ & $7.4 \pm 2.7$ & $7.8 \pm 2.4$ & 0.094 \\
\hline
\end{tabular}


lingula were found bilaterally as nodular in 180 sides $(55 \%)$, truncated in 102 sides $(31.2 \%)$, triangular in 39 sides (11.9\%), and assimilated in 6 sides $(1.8 \%)$. By comparison, we found that the nodular shape was most common (32.5\%) followed by assimilated $(26.2 \%)$, triangular $(22.2 \%)$ and truncated shapes (19\%). Bilateral shape (76\%) was found more often than the unilateral shape (24\%).

Considering that height of lingula varies in different populations. The study of Jansisyanot et al. [8] showed height of lingula to be $8.2 \pm 2.3 \mathrm{~mm}$ on Thai mandibles. Monnazzi et al. [15] reported the lingular height to be $5.82 \pm 0.43 \mathrm{~mm}$ in Brazil population. In Samantha and Kharb [21] study, the mean height of the lingula was found to be $5.5 \pm 2.02 \mathrm{~mm}$ and it was $58 \pm 2.1 \mathrm{~mm}$ on the right side and $5.2 \pm 1.9 \mathrm{~mm}$ on the left side which is comparatively less than that reported in other population groups. In Sekerci and Sisman [22] study, height of lingula on the right side was $8.03 \pm 1.73 \mathrm{~mm}$ and on the left side $7.82 \pm 1.79 \mathrm{~mm}$ with statistical difference between males and females on the right side. Similarly, in the present study, height of lingula on the right side was, $8.3 \pm 0.03 \mathrm{~mm}$ and on the left side $-7.4 \pm 0.04 \mathrm{~mm}$.

When performing the SSRO, the position of the lingula is of vital importance because the osteotomy is performed at the region around the lingula during the medial horizontal osteotomy [17]. In addition, the different locations of the lingula could be one of reasons for failure of an inferior mandibular nerve block. There are some anaesthetic protocols which proclaim the utilisation of long needles for the inferior mandibular nerve block. Use of appropriate length of the anaesthetic needle is important to avoid technical failure, needle fracture and perforation of the parotid gland according to the localisation of the lingula [20]. Sheonoy et al. [23] found the distance between anterior border and mandibular foremen $16 \mathrm{~mm}$. Samantha and Kharb [21] found the lingula was located at $20.0 \pm 2.4 \mathrm{~mm}$ from the anterior border of mandibular ramus, whereas in our study it was found to be $18.5 \mathrm{~mm}$. They also reported the lingual distance from posterior border of the ramus and the distance from mandibular notch $15 \pm 2.7$ and $15.4 \pm 2.7 \mathrm{~mm}$, respectively. These distances were presented as $16.9 \pm 3.5$ and $18.1 \pm 3.6 \mathrm{~mm}$ in our study. The mean distance from lingula to the anterior border of the mandibular ramus in Sekerci and Sisman [22] study was $16.77 \pm 2.74 \mathrm{~mm}$ and the distance from the lingula to the mandibular notch was
$15.32 \pm 2.46 \mathrm{~mm}$. In another study, Jansisyanot et al. [8] reported that the mean distance from the lingula to the anterior border of the mandibular ramus was $20.6 \pm 3.5 \mathrm{~mm}$ and the distance from the lingula to the mandibular notch was $16.6 \pm 2.9 \mathrm{~mm}$.

\section{CONCLUSIONS}

Additional information was provided to the literature concerning the shape, height and the location of the lingula in Southeast Region of Turkey in the present study. The results of this study will provide important morphometric information to prevent the complications in mandibular surgery.

\section{REFERENCES}

1. Acebal-Bianco F, Vuylsteke PL, Mommaerts MY, De Clercq CA (2000) Perioperative complications incorrective facial orthopedic surgery: a 5-year retrospective study. J Oral Maxillofac Surg, 58: 754-760.

2. Andrei F, Motoc AG, Didilescu AC, Rusu MC (2013) A 3D cone beam computed tomography study of the styloid process of the temporal bone. Folia Morphol, 72: 29-35.

3. Cavalcanti MG, Ruprecht A, Vannier MW (2002) 3D volume rendering using multislice $C T$ for dental implants. Dentomaxillofac Radiol, 31: 218-223.

4. de Souza Fernandes AC, Cardosa PM, Fernandes IS, de Moraes M (2013) Anatomic study for the horizontal cut of the sagittal split ramus osteotomy. J Oral Maxillofac Surg, 71: 1239-1244.

5. Devi R, Arna N, Manjunath KY, Balasubramanyam (2003) Incidence of morphological variants of mandibular lingula. Indian J Dent Res, 14: 210-213.

6. Fujimura K, Segami N, Kobayashi S (2006) Anatomical study of the complications of intraoral vertico-sagittal ramus osteotomy. J Oral Maxillofac Surg, 64: 384-389.

7. Gaia BF, Pinheiro LR, Umetsubo OS, Costa FF, Cavalcanti MG (2013) Comparison of precision and accuracy of linear measurements performed by two different imaging software programs and obtained from 3D-CBCT images for Le Fort I osteotomy. Dentomaxillofac Radiol, 42: 20120178.

8. Jansisyanont P, Apinhasmit W, Chompoopong S (2009) Shape, height and location of the lingual for sagittal ramus osteotomy in Thais. Clin Anat, 22: 787-793.

9. Kanno CM, de Oliveira JA, Cannon M, Carvalho AA (2005) The mandibular lingula's position in children as a reference to inferior alveolar nerve block. J Dent Child (Chic), 72: 56-60.

10. Kaufman E, Serman NJ, Wang PD (2000) Bilateral mandibular accessory foramina and canals: a case report and review of the literature. Dentomaxillofac Radiol, 29: 170-175.

11. Keros J, Kobler, P, Baucic I, Cabov T (2001) Foramen mandibulae as an indicator of successful conduction anesthesia. Coll Antropol, 25: 327-331.

12. Kositbowornchai $S$, Siritapetawee $M$, Damrongrungruang $T$, Khongkankong W, Chatrchaiwiwatana S, Khamanarong K, Chanthaooplee T (2007) Shape of the lingula and its localization by panoramic radiograph versus dry mandibular measurement. Surg Radiol Anat, 29: 689-694. 
13. Lopes PT, Pereira GA, Santos AM (2010) Morphological analysis of the lingula in dry mandibles of individuals on Southern Brazil. J Morphol Sci, 27: 136-138.

14. Maki K, Inou N, Takanishi A, Miller AJ (2003) Computer-assisted simulations in orthodontic diagnosis and the application of a new cone beam X-ray computed tomography. Orthod Craniofac Res, 6: 95-101.

15. Monnazzi MS, Passeri LA, Gabrielli MF, Bolini PD, de Carvalho WR, da Costa Machado H (2012) Anatomic study of the mandibular foramen, lingula and antilingula in dry mandibles, and its statistical relationship between the true lingula and the antilingula. Int J Oral Maxillofac Surg, 41: 74-78.

16. Murlimanju BV, Prabhu LV, Pai MM, Paul MT, Saralaya VV, Kumar CG (2012) Morphological study of lingula of the mandibles in South Indian population. Morphologie, 96: 16-20.

17. Muto T, Shigeo K, Yamamoto K, Kawakami J (2003) Computed tomography morphology of the mandibular ramus in prognathism: effect on the medial osteotomy of the sagittal split ramus osteotomy. J Oral Maxillofac Surg, 61: 89-93.

18. Nicholson ML (1985) A study of the position of the mandibular foramen in the adult mandible. Anat Rec, 212: 110-112.
19. Nirmale VK, Mane UW, Sukre SB, Diwan CV (2012) Morphological features of human mandible. Int J Recent Trends Sci Aechnol, 3: 33-43.

20. Palti DG, Almeida CM, Rodrigues AC, Andreo JC, Lima JE (2011) An anesthetic technique for the inferior alveolar nerve block: a new approach. J Appl Oral Sci, 19: 11-15.

21. Samanta PR, Kharb P (2012) Morphological analysis of the lingula in dry adult human mandibles of north Indian population. J Cranio-Maxillary Dis, 1: 7-11.

22. Sekerci AE, Sisman $Y$ (2014) Cone-beam computed tomography analysis of the shape, height, and location of the mandibular lingula. Surg Radiol Anat, 36: 155-162.

23. Shenoy V, Vijayalakshmi S, Saraswathi P (2012) Osteometric analysis of mandibular foramen in dry human mandibles. J Clin Diagn Res, 6: 557-560.

24. Smith GI, Brennan PA, Oh SS, Markus AF (2002) Modification of the Hunsuck sagittal split osteotomy using a nerve hook. Technical note. J Craniomaxillofac Surg, 30: 292-294.

25. Tuli A, Choudhry R, Choudhry S, Raheja S, Agarwal S (2000) Variation in shape of the lingual in the adult human mandible. J Anat, 197: 313-317.

26. Varma CL, Sameer PA (2013) Morphological Variations of Lingula in South Indian Mandibles. Res Rev J Med Health Sci, 2: 31-34. 